\title{
Demographic profile of patients diagnosed with intracranial meningiomas in two academic hospitals in Johannesburg, South Africa: \\ a 12-month prospective study
}

\author{
Kaunda Ibebuike ${ }^{1,3}, J_{\text {John Ouma }}^{2}$
}

1. Department of Neurosurgery, Chris Hani Baragwanath Academic Hospital, Johannesburg, South Africa

2. Department of Neurosurgery, Charlotte Maxeke Johannesburg Academic Hospital, Johannesburg, South Africa

3. Division of Neurosurgery, Department of Surgery, Imo State University Teaching Hospital, Orlu, Nigeria

\begin{abstract}
Background: Meningiomas are common brain tumours and display gender, racial and ethnic differences in their demographic profile. The demographic profile of our patients diagnosed with intracranial meningiomas is presented and compared with the literature.

Objectives: To determine the age, gender, racial and ethnic distribution of our patients diagnosed with intracranial meningiomas.

Methods: Consecutive patients (48 in number) seen at Charlotte Maxeke Johannesburg Academic Hospital (CMJAH) and Chris Hani Baragwanath Academic Hospital (CHBAH), Johannesburg, with histologically proven meningiomas over a 12 month period were recruited for the study.

Results: Meningiomas accounted for $33.8 \%$ of all primary brain tumours. The mean age of patients was $45.7 \pm 10.5$ years with a female-to-male ratio of 3.8:1. The mean age for male patients was $39.3 \pm 13.5$ years while that of female patients was $47.4 \pm 9.0$ years. The peak age range at presentation was in the fifth $(41.7 \%)$ decade. The highest frequency was among Black Africans $(75 \%)$ and Sotho ethnic nationality $(27.1 \%)$.

Conclusion: The study showed a female preponderance for intracranial meningiomas among our patients. Although intracranial meningiomas were more in frequency among Black Africans, the racial distribution mirrored our population distribution while the highest frequency was among Sotho ethnic nationality.
\end{abstract}

Key words: intracranial meningioma, demographic profile, age, gender, race, ethnic

DOI: http://dx.doi.org/10.4314/ahs.v14i4.24

\section{Introduction}

Although meningiomas are common intracranial neoplasms, they remain under-studied and under-reported..$^{1,2}$ However, over the years there has been growing interest in meningiomas with new questions and challenges relating to every aspect of meningiomas. ${ }^{2,3}$ Worldwide there has been consistent increase in the frequency of
Corresponding author:
Kaunda Ibebuike
Division of Neurosurgery
Department of Surgery
Imo State University Teaching Hospital
PMB 08, Orlu
Imo State, Nigeria
Phone: +2348063409555
E-mail: ibebuikeke@yahoo.com

occurrence of meningiomas and also studies confirm increase in occurrence with age as well as a female preponderance. $^{4-6}$ As our population ages due to increase in our life expectancy, a closer look at this disease in our environment is therefore justified.

The presentation of intracranial meningiomas displays racial/ethnic differences as can be seen between Caucasians, Africans and African-Americans. ${ }^{6}$ Meningiomas are more common in Africa than in North America and Europe ${ }^{6,7}$ and account for nearly $30 \%$ of all primary intracranial tumours in Africa. ${ }^{6}$ The information relating to the highest occurrence of meningiomas being in Africa ${ }^{7,8}$ adds to the challenge for a closer look at the demographic profile of this disease in our environment. This is in addition to the observation of a lack of such study in our environment. The geographical and ethnic differences displayed by meningiomas ${ }^{4,7}$ present South Africa as a suitable environment for studying the demographic profile of intracranial meningiomas because of her peculiar multiracial and multiethnic setting. 
of the Witwaterstand. The study was over a period of were taken off the study due to the absence of a final 12 months (13th July 2009 - 12th July 2010). Approval histological diagnosis. The data obtained from the pafor the study was obtained from the Human Research tients were analysed by the use of Epi InfoTM 2002. Ethics Committee (Medical) of the University. While Data are presented as median, mean (range), frequency CMJAH is located within the city centre in Parktown, and percentages.

CHBAH (largest hospital in South Africa) is located in Statistical diagram using tables was created to highlight Soweto. They serve as tertiary hospitals for Gauteng the findings.

Province and cares for public patients although CM-

$\mathrm{JAH}$ has a wing for private patients. They also serve

as referral hospitals for Provincial Hospitals in Mpu- During the 12 months study period, 48 consecutive pamalanga and North West Provinces in South Africa. tients (out of 142 patients with primary brain tumours) Consecutive patients seen at the both hospitals with histologically proven intracranial meninoioma dur- pital $(\mathrm{CMJAH})$ and the Chris Hani Baragwanath Acaing the study period were recruited for the study. We demic Hospital (CHBAH), Johannesburg had histologiobtained data from the patients using an investigator- cally confirmed intracranial meningioma with a hospital administered questionnaire. All patients were seen as distribution of 27 patients at CHBAH and 21 patients in-patients. Diagnosis was made after detailed history at CMJAH. Frequency of distribution of intracrania

meningiomas among primary brain tumours (table 1 )

Table 1 show that meningiomas $(33.8 \%)$ had the highest frequency among primary brain tumours during the study period.

\begin{tabular}{lll}
$\begin{array}{l}\text { Table 1: Frequency of distribution of intracranial meningiomas among primary brain } \\
\text { tumours } \\
\text { Diagnosis }\end{array}$ & Percentage \\
\cline { 1 - 2 } \multicolumn{1}{c}{ Frequency } & & \\
\cline { 1 - 2 } Meningioma & 48 & $33.8 \%$ \\
Pituitary adenoma & 35 & $24.6 \%$ \\
Glioma & 32 & $22.5 \%$ \\
Craniopharyngioma & 4 & $2.8 \%$ \\
Ependymoma & 4 & $2.8 \%$ \\
Medulloblastoma & 4 & $2.8 \%$ \\
Schwannoma & 3 & $2.1 \%$ \\
Myeloma & 3 & $2.1 \%$ \\
Lymphoma & 2 & $1.4 \%$ \\
Epidermoid cyst & 2 & $1.4 \%$ \\
PCNSL & 1 & $0.7 \%$ \\
Meningeal haemangiopericytoma & 1 & $0.7 \%$ \\
Haemangioblastoma & 1 & $0.7 \%$ \\
Atypical teratoid/rhabdoid tumour & 1 & $0.7 \%$ \\
PNET & 1 & $0.7 \%$ \\
Total & 142 & $100 \%$ \\
\hline PCNSL: Primary Central Nervous System Lymphoma &
\end{tabular}

PCNSL: Hid

PNET: Primitive Neuroectodermal Tumour

\begin{tabular}{|c|c|c|}
\hline Age group in years & Number of patients & Percent \\
\hline \multicolumn{3}{|l|}{ Both genders } \\
\hline $21-30$ & 4 & $8.3 \%$ \\
\hline $31-40$ & 9 & $18.7 \%$ \\
\hline $41-50$ & 20 & $41.7 \%$ \\
\hline $51-60$ & 13 & $27.1 \%$ \\
\hline $61-70$ & 2 & $4.2 \%$ \\
\hline Total & 48 & $100 \%$ \\
\hline \multicolumn{3}{|l|}{ Males } \\
\hline $21-30$ & 3 & $30 \%$ \\
\hline $31-40$ & 2 & $20 \%$ \\
\hline $41-50$ & 2 & $20 \%$ \\
\hline $51-60$ & 2 & $20 \%$ \\
\hline $61-70$ & 1 & $10 \%$ \\
\hline Total & 10 & $100 \%$ \\
\hline \multicolumn{3}{|l|}{ Females } \\
\hline $21-30$ & 1 & $2.6 \%$ \\
\hline $31-40$ & 7 & $18.4 \%$ \\
\hline $41-50$ & 18 & $47.4 \%$ \\
\hline $51-60$ & 11 & $29.0 \%$ \\
\hline $61-70$ & 1 & $2.6 \%$ \\
\hline Total & 38 & $100 \%$ \\
\hline
\end{tabular}

The mean age of all patients with intracranial meningi- Gender, Race and Ethnic Nationality (Home language) omas was $45.7 \pm 10.5$ years (range 23-67 years, median distribution (table 3)

46.5 years). The mean age for male patients was 39.3 The gender, race and ethnic nationality is shown in \pm 13.5 years (range 23-61 years) while that of female table 3 with females (79.2\%), Black Africans (75\%), patients was $47.4 \pm 9.0$ years (range 27-67 years). The and Sotho ethnic nationality (27.1\%) having the highest peak age range was in the age group 41-50 years percentages in the different categories. There were 4 accounting for $41.7 \%$ of patients with meningiomas $(8.3 \%)$ foreign nationals from neighbouring Southand corresponding to the fifth decade of life. (Table 2) ern African countries. 


\begin{tabular}{lcc}
\multicolumn{2}{l}{ Table 3: Gender, Race and Ethnic Nationality (Home language) } \\
\hline Vastribution \\
\hline Variable & Number of patients & Percent \\
\hline Gender & 10 & \\
Male & 38 & $20.8 \%$ \\
Female & 48 & $79.2 \%$ \\
Total & & $100 \%$ \\
& & \\
Race & 36 & $75 \%$ \\
Black African & 6 & $12.5 \%$ \\
White & 4 & $8.3 \%$ \\
Coloured & 2 & $4.2 \%$ \\
Indian & 0 & $0.0 \%$ \\
Asian & 48 & $100 \%$ \\
Total & & \\
& 13 & \\
Ethnic Nationality (Home language) & \\
Sotho & 5 & $27.1 \%$ \\
Zulu & 5 & $10.4 \%$ \\
English & 5 & $10.4 \%$ \\
Afrikaner & 5 & $10.4 \%$ \\
Tswana & 5 & $10.4 \%$ \\
Xhosa & 4 & $10.4 \%$ \\
Foreign National & 3 & $8.3 \%$ \\
Pedi & 2 & $6.3 \%$ \\
Indian & 1 & $4.2 \%$ \\
Tshivenda & 48 & $2.1 \%$ \\
Total & & $100 \%$ \\
\hline & &
\end{tabular}

\section{Discussion}

There are few prospective studies on histologically proven intracranial meningiomas in the literature. The study was intended to be a Pilot study with the aim of further research based on the findings of the preliminary results after the first 12 months. Continuation of the study was designed and included profiling DNA copy number changes in South African meningiomas. However, funding was not available to continue the study. Hence due to the short study period, the results were displayed in descriptive terms for comparison with other published data.

The relative frequency of intracranial meningiomas $(33.8 \%)$ in this study compares with other studie ${ }^{5,9-1}$ which showed similar high relative frequency of intracranial meningiomas among primary brain tumours. The findings in our study show that meningiomas were the

most common primary intracranial tumours among adults seen in our institutions. When adjusted for number of patients per year, the findings (48 patients per year) in our study rate highest compared to that of Das et $\mathrm{al}^{11}$ in Singapore (41 patients per year), Fynn et $\mathrm{a}^{12}$ in Pretoria (17.3 patients per year), Gasparetto et $\mathrm{a}^{13}$ in Brazil (15.6 patients per year), QuiñonesHinojosa et $\mathrm{al}^{14}$ in US (9.6 patients per year), Jaggon and $\mathrm{Char}^{15}$ in Jamaica (5.3 patients per year) and Mezue et $\mathrm{al}^{16}$ in Nigeria (7.6 patients per year). The detection rate for central nervous system tumours have improved in our hospitals through the increasing availability of modern diagnostic neuroimaging facilities in our hospitals including the ease of accessibility by public patient who are not required to pay for diagnostic neuroimaging in public hospitals. These are performed free for our public patients in our public hospitals and may have contributed to the high trend in the relative frequency of meningiomas in this study.
Meningiomas affect women more often than men with a male-to-female ratio ranging from 1:1.4 to 1:2.8.6 Our study showed a female-to-male ratio of 3.8:1 and compares with the findings of Idowu et al ${ }^{5}$ which revealed a female-to-male ratio of 4.2:1 in both age group, and 4:1 in the adult population. It, however, contrasts with the findings of Jaggon and Char ${ }^{16}$ in Jamaica (2.8:1), Fynn et $\mathrm{al}^{12}$ in Pretoria, South Africa (2.5:1) and Gasparetto et al13 in Brazil (2:1). It is also a sharp contrast to, Mezue et $\mathrm{al}^{13}$ in Enugu, Nigeria (1.1:1) and Odebode et $\mathrm{al}^{17}$ in Ibadan, Nigeria (1.3:1). The findings in our study also differs from earlier observations in the literature, ${ }^{6,8,18}$ which report equal gender distribution or a male predominance among Africans. However, the female-tomale ratio of 1:3 in the third decade of life in our study is in keeping with reports in the literature which showed no predominance in women in their fourth decade and below. $8,19,20$

Racial/ethnic differences in the frequency of intracranial meningioma have been reported between Caucasians, Africans and African-Americans. ${ }^{6}$ In our study, the racial distribution of patients diagnosed with intracranial meningiomas tended to mirror the population distribution of Gauteng Province with Black Africans accounting for $75 \%$ of patients and other races (White/Coloured/Indian) accounting for 25\%. The percentage of the population groups in Gauteng Province as captured in the 2001 Census in South Africa showed Black African 73.8\%; Coloured 3.8\%; Indian or Asian $2.5 \%$ and White $19.9 \%$ with a total population of $8,837,178$ persons. ${ }^{21}$ Our study findings indicating a higher distribution of intracranial meningiomas among the black race $(75 \%)$ therefore appear to reflect the predominantly black population in our environment. In our study Indians had the lowest rate and there was no Asian, in keeping with the findings in other studies elsewhere. ${ }^{8,22-24}$ In a recent US study, ${ }^{10}$ reported rates for Black Non-Hispanics are slightly higher (6.67) than for White Non-Hispanic and Hispanics (5.90 and 5.94, respectively).

Meningiomas are said to constitute $30 \%$ of brain tumours in Bantus in Africa ${ }^{25}$ and this compares with the high frequency among Sotho ethnic nationality $(27.1 \%)$ noted in our environment, despite the dominant ethnic group in Johannesburg, Gauteng Province, ${ }^{21}$ being Zulu (10.4\%). The percentage distribution of ethnic nationality by home language in Gauteng Province as captured in the 2001 Census in South Africa showed frikaans 14.4\%; English 12.5\%; Ndebele 1.9\%; Xhosa $7.6 \%$; Zulu $21.5 \%$; Pedi $10.7 \%$; Sotho $13.1 \%$; Tswana $8.4 \%$; Swati $1.4 \%$; Tshivenda $1.7 \%$; Xitsonga $5.7 \%$ and others $1.0 \% .{ }^{21}$ There is no definite explanation for the high frequency of intracranial meningiomas among the Sotho ethnic nationality, though the influence of genetic factors may partly play a role. Other possible reasons may be the fact that patients are referred to our Gauteng teaching hospitals from other provinces/areas that do not have teaching/tertiary hospitals and this may merely reflect the population make up of those provinces/areas. The relative contributions of risk factors including environmental, hormonal or genetic factors to this sociodemographic variation are yet to be determined in our environment.

Meningiomas have a tendency to occur from the third to sixth decades of life ${ }^{26,17}$ and peaks between the ages of 40-60 years. ${ }^{27}$ Meningiomas are rare in patients younger than 20 years. $^{25}$

This compares with the findings in our study which showed the peak age range in the fifth (41.7\%) and sixth (27.1\%) decades for both gender. Females showed similar peak age range of $47.4 \%$ and $29 \%$ respectively, whereas males had a fairly equal spread with the highes peak age range in the third $(30 \%)$ decade of life. There was no meningioma in infancy and childhood in our study. This is in keeping with the rarity of meningiomas in infants and children, ${ }^{19,26,28,29}$ though this finding in our study may have been influenced by the short period of our study.

The mean age at diagnosis of meningiomas is 45 years. ${ }^{29}$ In our study, the youngest patient was 23 years old; the median age was 46.5 years while the mean age was 45.7 years. This corresponds with other reports. ${ }^{12,15,29} \mathrm{~A}$ lower mean age of 40 years was noted by Odebode et al1 ${ }^{7}$ in Ibadan, though this may have been influenced by the low number of patients $(\mathrm{n}=35)$ in their study. A higher mean age of 52.7 years was noted in the study by Quiñones-Hinojosa et $\mathrm{al}^{14}$ in the United States. However, their study assessed pre-operative factors affecting resectability of giant intracranial meningiomas $(\geq 5 \mathrm{~cm}$ in the longest dimension). From their study, one can infer the likelihood of a shift towards older age group in large sized meningiomas. Large sized meningiomas are more likely to reflect long standing disease for these slow-growing and generally benign tumours, and therefore their likely occurrence in the older age group. 
When compared to other studies, the age range (23-67 2. Campbell BA, Jhamb A, Maguire JA, Toyota B, years) in our study differs from that of Fynn et $\mathrm{al}^{12}$ in Ma R. Meningiomas in 2009: Controversies and FuPretoria (2-83 years), Odebode et $\mathrm{al}^{17}$ in Ibabdan (9-77 ture Challenges. A J Clin Oncol 2009;32:73-85.

years), and Jaggon and Char ${ }^{15}$ in Jamaica (13-80 years). 3. Drummond KJ, Zhu J, Black PM. MeningiIt compares with the findings of Gasparetto et al13 in omas: Updating Basic Science, Management and Brazil (23-81 years), in not having any patient in the pae- Outcome. Neurologist 2004;10:113-30.

diatric age group but contrasts with it by the lack of pa- 4. Claus EB, Bondy ML, Schildkraut JM, Wiemels tients from the eight decade upwards in our series. The JL, Wrensch M, Black PM. Epidemiology of Intracraabsence of meningiomas in the paediatric age group in nial Meningioma. Neurosurgery 2005;57:1088-95. this study may have been influenced by the short study 5. Idowu O, Akang EEU, Malomo A. Symptomatic period, which may have limited the possibility of iden- Primary Intracranial neoplasms inNigeria, West Africa. tifying patients in the paediatric age group within the Journal of Neurological Sciences (Turkish). 2007;24:212-8. study period. And the absence of meningiomas among 6. Haddad G, Turkmani A. Meningioma. eMedipatients from the eight decade upwards in our study cine Nov 3, $2011 \mathrm{http}: / /$ emedicine.medscape.com/ may reflect a cautious approach to operative interven- article/1156552-overview. (accessed 11 Feb, 2013). tion among the elderly who fall within some of the 7. Ohaegbulam SS. Geographical Neurosurgery. Neurol patient-related factors prognostic of a high postop- Res 1999;21:161-70.

erative morbidity which includes advanced patient age, 8. Bondy ML, Ligon BL. Epidemiology and aetiology co-morbid conditions including diabetes mellitus and of intracranial meningiomas: a review. I Neurooncal severe preoperative neurological impairment.

\section{Conclusion}

The study showed a female preponderance for in tracranial meningiomas among our patients while the highest frequency was among Sotho ethnic nationality. Although intracranial meningiomas were more in distribution among Black Africans (75\%) compared to other races (White/Coloured/Indian/Asian) (25\%), the racial distribution mirrored our population distribution (Black African-73.8\%, White/Coloured/Indian/ Asian- 26.2\%). Genetic and environmental factors may be responsible for some of the findings in this study and further study may be required to identify these factors. Preferably a multicentre collaborative study in different Provinces in South Africa may help to have a cleare picture of the demographic profile of this tumour in our environment. And we do hope that the observations in this study will serve as an important baseline for the design and interpretation of future studies on the demographic profile of intracranial meningiomas in our environment.

Abbreviations: CMJAH, Charlotte Maxeke Johannesburg Academic Hospital; CHBAH, Chris Hani Baragwanat Academic Hospital; CT, computed tomography; MRI, magnetic resonance imaging; PCNSL, Primary Central Nervous System Lymphoma; PNET, Primitive Neuroectodermal Tumour.

\section{References}

1. Lusis E, Gutmann DH. Meningioma: an update. Current Opinion in Neurology2004;17:687-92 of intracranial meningiomas: a review. J Neuroonco 9. Idowu OE, Apemiye RA. Delay in presentation and diagnosis of adult primary intracranial neoplasms in a tropical teaching hospital: A pilot study. International Journal of Surgery 2009;7:396-8.

10. Wiemels J, Wrensch M, Claus EB. Epidemiology and etiology of meningioma. J Neurooncol 2010;99:307-

11. Das A, Chapman CAT, Yap WM. Histological subtypes of symptomatic central nervous system tumours in Singapore. I Neurol Neurosurg Psycbiatry 2000;68:372-4.

12. Fynn E, Khan N, Ojo A. Meningioma - a review of 52 cases. SA Journal of Radiology 2004:3-5

13. Gasparetto EL, Leite CC, Lucato LT, Barros CV, Marie SKN, Santana P, et al. Intracranial meningiomas: magnetic resonance imaging findings in 78 cases. Arquivos de Neuro-Psiquiatria 2007;65:610-4.

14. Quiñones-Hinojosa A, Kaprealian T, Chaichana KL, Sanai N, Parsa AT, Berger MS, et al. Pre-Operative Factors Affecting Resectability of Giant Intracranial Meningiomas. Can J Neurol Sci 2009;36:623-30.

15. Jaggon JR, Char G. Epidemiologic Data on Meningiomas in Jamaica: The First from the Caribbean. The Internet Journal of Third World Medicine 2007;5: DOI:10.5580/1840.

16. Mezue WC, Ohaegbulam SC, Ndubuisi CC, Chikani MC, Achebe DS. Intracranial meningiomas managed at Memfys hospital for neurosurgey in Enugu, Nigeria. I Neurosci Rural Pract. 2012;3:320-323

17. Odebode TO, Akang EE, Shokunbi MT, Malomo AO, Ogunseyinde AO. Factors influencing visual and clinical outcome in Nigerian patients with cranial meningioma. I of Clinical Neurosciences 2006;13:649-54 18. Haddad G, Al-Mefty O. Meningiomas: An overview. In: Wilkins RH, Rengachary SS, editors. Neurosurgery. 2nd ed. New York: McGraw-Hill; 1998. p. 833-41. 19. Al-Mefty O, Abdulrauf S, Haddad GF. Meningiomas. In: Winn HR, editor. Youmans Neurological Surgery. Philadelphia: Elsevier Saunders; 2011. p. 1426 1449

20. Sutherland GR, Florel R, Louw D, et a. Epidemiology of primary intracranial neoplasms in Manitoba, Canada. Canadian J Neurol Sci 1987;14:586

21. South African National Census of 2001. Statistics South Africa, 2003.http://www.statssa.gov. $\mathrm{za} /$ census01/html/CInbrief/CIB2001.pdf(accessed 1 May 2013)

22. Preston-Martin S, Henderson BE, Peterm JM. Descriptive epidemiology of central nervous system neoplasm in Los Angeles Country. Annals NY Acad Sci 1982;381:202-8.

23. Preston-Martin S. Descriptive epidemiology of pri- mary tumours of the brain, cranial nerves and cranial 1989;8:283-95.

24. Ameli N, Haddadian A, Kamalian N. Incidence of intracranial tumours in Iran. A survey of 1500 verified cases. Neurosurg Rev 1979;2:67-71.

25. Castillo GC. Meningioma, Brain. eMedicine Apr 27, $2007 \mathrm{http}: / /$ emedicine.medscape.com/article/341624 overview. (accessed 15 Feb, 2009).

26. Rockhill J, Mrugala M, Chamberlain MC. Intracranial meningiomas: an overview of diagnosis and treatment. Neurosurg Focus 2007;23:E1

27. Al-Hadidy AM, Mani WS, Mahafza WS, Al-Naja MS, Al-Nadii MM. Intracranial Meningioma. J Med J 2007;41:37-51.

28. Longstreth WJJ, Dennis LK, McGuire VM, (ntracnenial Mioma. Cancer 1993;72:639-48.

9. Al-Mefty O, Heth J. Meningiomas. In: Rengachary SS, Ellenbogen RG, editors. Principles of Neurosurgery. 2nd ed. New York: Elsevier Mosby; 2005. p. $487-500$ 